九州大学学術情報リポジトリ

Kyushu University Institutional Repository

\title{
Study on Characteristics of Paper Laminated with Biodegradable Plastics, (2): Analytical Characterization on Chemical and Biological Degradation
}

\section{Mayumi, Ayaka}

Laboratory of Bioresources Chemistry, Division of Biomaterial Science, Department of Forest and Forest Products Sciences, Graduate School of Bioresource and Bioenvironmental Sciences, Kyushu University

\section{Kanie, Osamu}

Laboratory of Bioresources Chemistry, Division of Biomaterial Science, Department of Forest and Forest Products Sciences, Graduate School of Bioresource and Bioenvironmental Sciences, Kyushu University

\section{Kitaoka, Takuya}

Laboratory of Bioresources Chemistry, Division of Biomaterial Science, Department of Forest and Forest Products Sciences, Graduate School of Bioresource and Bioenvironmental Sciences, Kyushu University

Wariishi, Hiroyuki

他

https://doi.org/10.5109/4530

出版情報：九州大学大学院農学研究院紀要. 48 (1/2)，pp. 85-95，2003-10-01. Faculty of Agriculture, Kyushu University

バージョン：

権利関係: 


\title{
Study on Characteristics of Paper Laminated with Biodegradable Plastics, 2. Analytical Characterization on Chemical and Biological Degradation
}

\author{
Ayaka MAYUMI*, Osamu KANIE*, Takuya KITAOKA', \\ Hiroyuki WARIISHI and Hiroo TANAKA \\ Laboratory of Bioresources Chemistry, Division of Biomaterial Science, Department of \\ Forest and Forest Products Sciences, Faculty of Agriculture, \\ Kyushu University, Fukuoka 812-8581, Japan \\ (Received March 10, 2003 and accepted July 15, 2003)
}

\begin{abstract}
Chemical and biological degradation behavior of commercial polylactide (PLA) film, poly (L-lactide) (PLLA) and poly (DL-lactide) (PDLLA) was investigated by gravimetric analysis, $\mathrm{X}$-ray diffractometry, differential scanning calorimetry and Fourier transform Raman (FT-Raman) spectroscopy. The PLA film exhibited an extremely high resistance to acid hydrolysis by hydrochloric acid, although alkaline treatment with a dilute sodium hydroxide brought about the quick decomposition of PLAs, not being reflected in their crystallinity. The $\mathrm{X}$-ray and FT-Raman results implied the immediate decomposition occurring only on the PLA surfaces. These phenomena were observed both for crystalline PLLA and amorphous PDLLA; however, at temperature above their glass transition points, the PDLLA was greater deteriorated than the PLLA under acidic conditions, whereas in the alkaline system the tendency was reversed. On the biological degradation, the PLA film remained almost unchanged even after buried in soil for six months, as supported by various analytical results. Possibly, the PLA-related products commercially available have lower biodegradability than expected, and thus it was indicated that a strategic material design, e.g., the utilization of paper-based ecomaterials whose practicality and biodegradability can be compatible with each other, is of significance for high performance composite-manufacturing with biodegradable plastics.
\end{abstract}

\section{INTRODUCTION}

Many plastic products manufactured from finite petroleum resources have provided direct and indirect impacts on natural environments, e.g., global warming, exhaustion of the resources, waste disposal and a fatal damage on ecosystem by toxic or endocrine-disrupting chemicals. Thus, the social consciousness on environmental protection and resource circulation has recently been raised as critical problems all over the world. Discrimination of right and wrong for material civilization is an immortal problem, although a lot of materials and products are indispensable for our life style in actual society. Therefore, a new material compatible for natural environments, called an ecomaterial, has been required; and thus various biodegradable plastics have been actively developed.

In particular, polylactide (PLA) is one of typical biodegradable plastics, which can be

\footnotetext{
* Laboratory of Bioresources Chemistry, Division of Biomaterial Science, Department of Forest and Forest Products Sciences, Graduate School of Bioresource and Bioenvironmental Sciences, Kyushu University, Fukuoka 812-8581, Japan

+ Corresponding author (E-mail: tkitaoka@agr.kyushu-u.ac.jp)
} 
chemically produced from L-lactic acid obtained by microbial transformation of biomass waste (Nolasco-Hipolito et al., 2001; Mohanty et al., 2000). These plastic materials have been studied in many aspects: biocompatibility, biodegradability and physical properties (Jacobsen et al., 1999; Amass et al., 1998; Anderson et al., 1997). The material performance has generally been reduced as the biocompatible characteristics are improved (Ikada et al., 2000). On a material design, the combination of biodegradable products is of very interest and of significance for achieving the coexistence of performance and eco-compatibility, and thus we tried to prepare the paper-PLA composites and investigated their biodegradability (Kanie et al., 2002). However, the PLA films and the PLA portion of their laminated paperboards did not degrade in soil even after six months, although the paper-based substrates were rapidly deteriorated. Thus, there is much room for doubt about the PLA-related biodegradability reported so far, especially with regard to the non-enzymatic hydrolysis that a PLA with a high molecular weight is converted to the PLA oligomers at the initial stage of biodegradation (Tsuji et al., 2001). In any case, the detailed behavior of the PLA decomposition must be elucidated to newly devise the biomass-based ecomaterials enforced by the PLA.

In this study, to obtain the fundamental understandings for PLA deterioration the PLA-degrading behavior on chemical and biological degradation was investigated by gravimetric and various chemical analyses: X-ray diffractometry (XRD), differential scanning calorimetry (DSC) and near infrared-Fourier transform (NIR-FT) Raman analysis. Weight loss of the PLA samples on acid or alkaline hydrolysis was linked to the results obtained by the chemical analyses, and the findings were applied to account for the PLA degradation.

\section{MATERIALS AND METHODS}

\section{Materials}

Poly (L-lactide) (PLLA) and poly (DL-lactide) (PDLLA) were provided by Birmingham Polymers Co. Ltd., USA. Commercial PLA film (Ecoloju; $25 \mu \mathrm{m}$; biaxially oriented; Mitsubishi Plastics Co. Ltd., Japan) was used as it was, and as laminated on the paperboard (Card B, Ide Paper MFG Co. Ltd., Japan). Commercial polyethyleneterephtalate (PET; $23 \mu \mathrm{m}$; biaxially oriented) film was purchased from Goodfellow Cambridge Co. Ltd., UK. Other chemicals were reagent grade (Wako Pure Chemical Industries Co. Ltd., Japan) and used without further purification.

\section{Procedures}

The PLA film and the PLA-laminated paperboard were buried in soil at Kami-ohshima, Tsukuba city, Ibaragi (the factory site) for six months, as referred to our previous study (Kanie et al., 2002). Sample specimens (0.1 g) were immersed in $35 \mathrm{ml}$ of 0-1 $\mathrm{M}$ hydrochloric acid or in $35 \mathrm{ml}$ of $0-1 \mathrm{M}$ sodium hydroxide at room temperature for a designated time: $0,0.5,1,2,4$ or 8 hours. These samples after the in-soil burial test or the chemical treatments were washed thoroughly with deionized water, and then were subjected to the following analyses after air-dried. 


\section{Analyses}

Sample weight that had been measured beforehand was compared with that after treated, and the remaining weight ratio was calculated by dividing the sample weight after treated by the original sample weight. XRD analysis was carried out using an X-ray diffractometer (XD-D1, Shimadzu Co. Ltd., Japan) with $\mathrm{CuK} \alpha$ radiation under X-ray generation conditions at $30 \mathrm{kV}$ and $40 \mathrm{~mA}$. The scanning rate and range were $4 \% \mathrm{~min}$ and $5^{\circ}-40^{\circ}$ as $2 \theta$, respectively. Crystallinity (X) was obtained by a following equation; $\mathrm{X}(\%)$ $=\mathrm{Ic} /[\mathrm{Ic}+\mathrm{Ia}] \times 100$, where the Ic is an $\mathrm{X}$-ray intensity in crystalline region and the Ia is that in amorphous region. Thermodynamic characteristics were determined using a DSC apparatus (DSC-50, Shimadzu Co. Ltd., Japan) at the heating rate of $10^{\circ} \mathrm{C} / \mathrm{min}$ from $20^{\circ}$ to $200^{\circ} \mathrm{C}$ or of $20^{\circ} \mathrm{C} / \mathrm{min}$ from $20^{\circ}$ to $120^{\circ} \mathrm{C}$ for measuring melting point (m.p.) or glass transition point (Tg), respectively, in an atmosphere of nitrogen according to JIS K7121. NIR-FT Raman analysis was performed using a Perkin Elmer System 2000 spectrometer. The laser for excitation was a diode Nd:YAG at $1064 \mathrm{~nm}$. All spectra were obtained in the $180^{\circ}$ scattering geometry by using an InGaAs detector at a laser power of $600 \mathrm{~mW}$ and by averaging 200 scans with a resolution of $4 \mathrm{~cm}^{-1}$.

\section{RESULTS AND DISCUSSION}

\section{Chemical degradation of PLA products}

Figure 1 shows the weight loss of PLA and PET films treated by acidic or alkaline solution. Acidic treatment with $0-1 \mathrm{M} \mathrm{HCl}$ gave no impact on the decomposition of both samples for 0-4 hours; however, the alkaline steeping test resulted in the quick decomposition of the PLA film with time, although the PET film was not affected in weight at all. More than $50 \%$ of the PLA film was chemically decomposed for 4 hours. Figure 2 displays

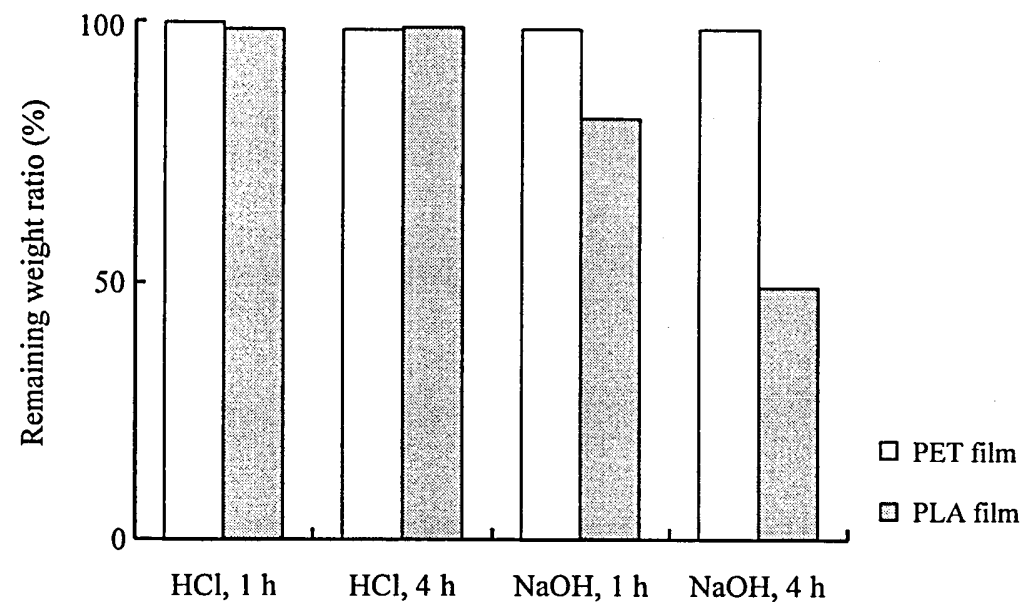

Fig. 1. Weight loss of PLA and PET films by chemical treatments with $1 \mathrm{M} \mathrm{HCl}$ or with $1 \mathrm{M} \mathrm{NaOH}$ at $20^{\circ} \mathrm{C}$. 
the changes in the sample weight of PLLA and PDLLA treated by $1 \mathrm{M} \mathrm{HCl}$ or by $1 \mathrm{M} \mathrm{NaOH}$ for 4 hours at different temperature; $20^{\circ}, 60^{\circ}$ or $80^{\circ} \mathrm{C}$. At any case, the PLA products showed a high resistance to the acidic circumstances. In contrast, the alkali treatment brought about an obvious decrease both in the PLLA and the PDLLA. Especially, the PDLLA was degradable even at room temperature; however, at $80^{\circ} \mathrm{C}$ the tendency was reversed.

Figure 3 illustrates the X-ray diffraction patterns of PLA film (a), PET film (b), PLLA beads (c) and PDLLA beads (d). Table 1 represents the crystallinity obtained from the results in Fig. 3. Strong singlet peak of the PLA film and the PET film appeared at $16.5^{\circ}$ and $25.9^{\circ}$, respectively, and two peaks of the PLLA were observed at $16.9^{\circ}$ and $19.3^{\circ}$. The PDLLA had no crystallinity, being amorphous. Commercial films were biaxially oriented to improve their physical properties, and thus ca. $90 \%$ crystallinity was achieved. The PLLA showed lower crystallinity; ca 77\% than the PLA film, even though a higher resistance was demonstrated in an alkaline system at room temperature. The alkaline hydrolysis occurs at an amorphous region rather than at a crystalline one, and thus even at room temperature the PDLLA was decomposed rapidly. Figure 4 shows the time course of

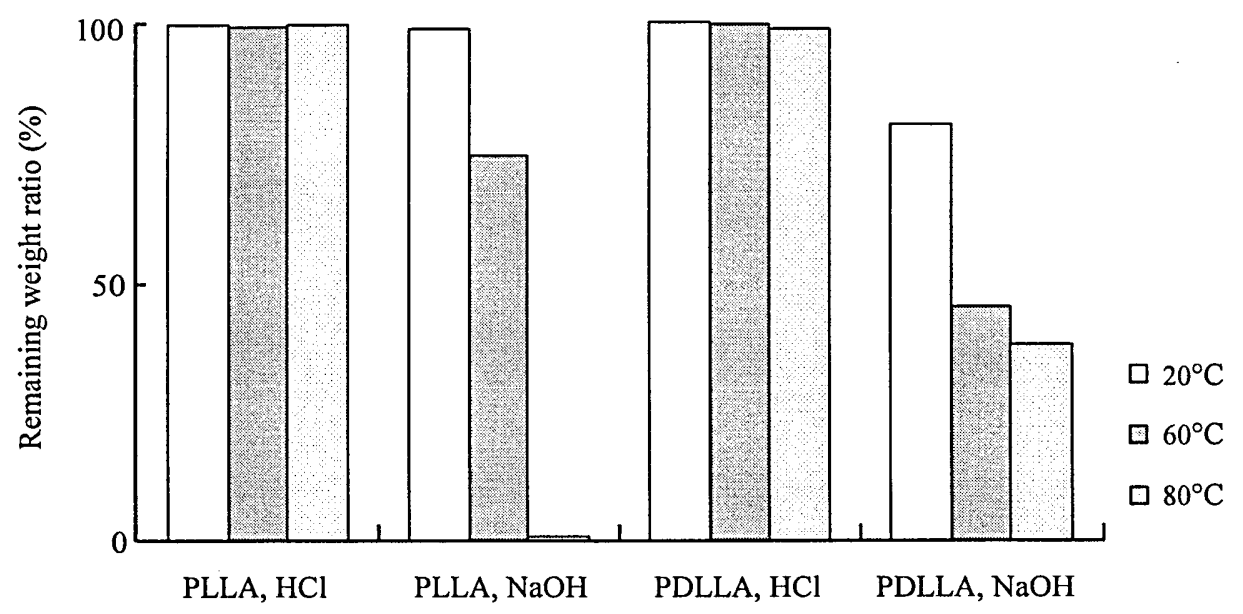

Fig. 2. Weight loss of PLLA and PDLLA by chemical treatments with $1 \mathrm{M} \mathrm{HCl}$ or with $1 \mathrm{M} \mathrm{NaOH}$ at various temperatures for 4 hours.

Table 1. Crystallinity of PLA film, PET film, PLLA and PDLLA.

\begin{tabular}{lc}
\hline Sample & Crystallinity (\%) \\
\hline PLA film & 89.3 \\
PET film & 92.8 \\
PLLA & 76.9 \\
PDLLA & amorphous \\
\hline
\end{tabular}




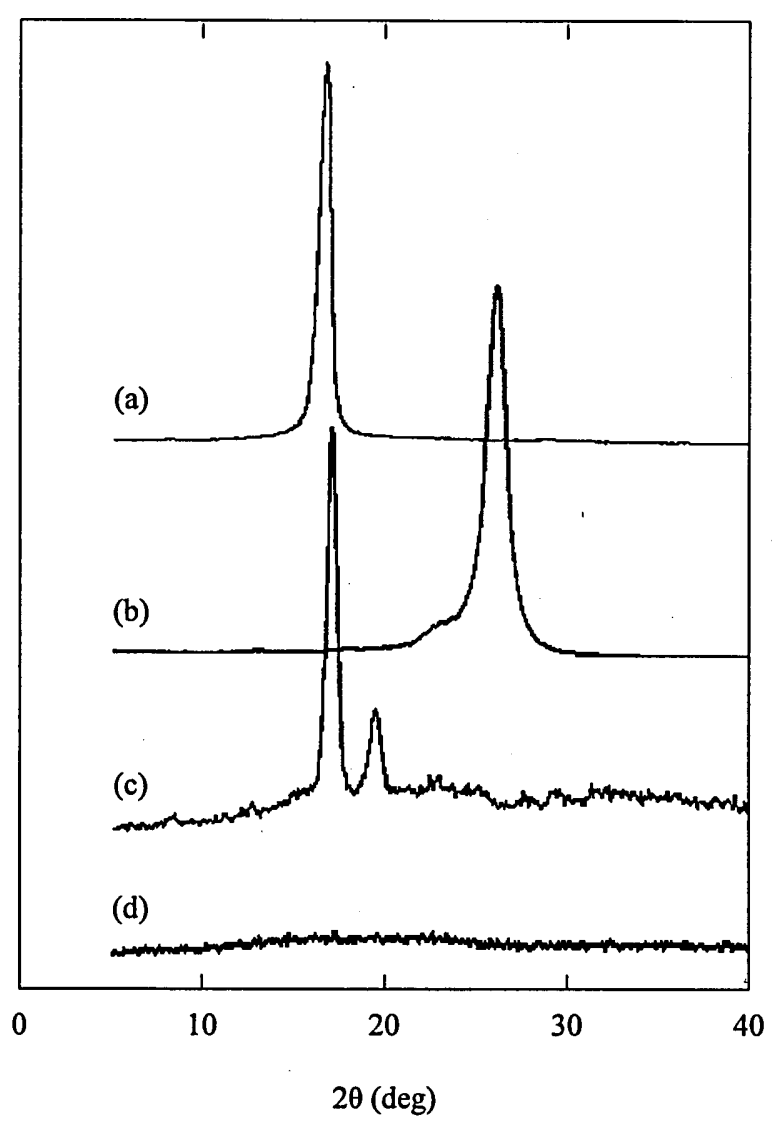

Fig. 3. X-ray diffraction patterns of PLA film (a), PET film (b), PLLA (c) and PDLLA (d).

changes in the crystallinity of the PLA film and the PET film by acidic or alkali treatment. No appropriate variation was observed under the testing conditions, and thus it was suggested that the alkali decomposition immediately proceeded only on the sample surfaces without destroying the crystalline structure by the alkaline intrusion.

\section{Thermodynamic and Raman characteristics}

Figure 5 profiles the DSC curves of PLA film (a), PLLA (b) and PDLLA (c), and Table 2 lists their m.p. and Tg. The PLA film displayed m.p. ca. $166^{\circ} \mathrm{C}$ and $\mathrm{Tg}$ ca. $70^{\circ} \mathrm{C}$. The PLLA showed m.p. ca. $177^{\circ} \mathrm{C}$ and slight Tg ca. $66^{\circ} \mathrm{C}$. The PDLLA indicated only $\mathrm{Tg} 55^{\circ} \mathrm{C}$. These thermodynamic characteristics accounted for the chemical degradability dependent on the treatment temperature, as shown in Fig. 2. After all, the alkali accessibility was possibly promoted by loosing the polymer chains in the amorphous region as the tem- 


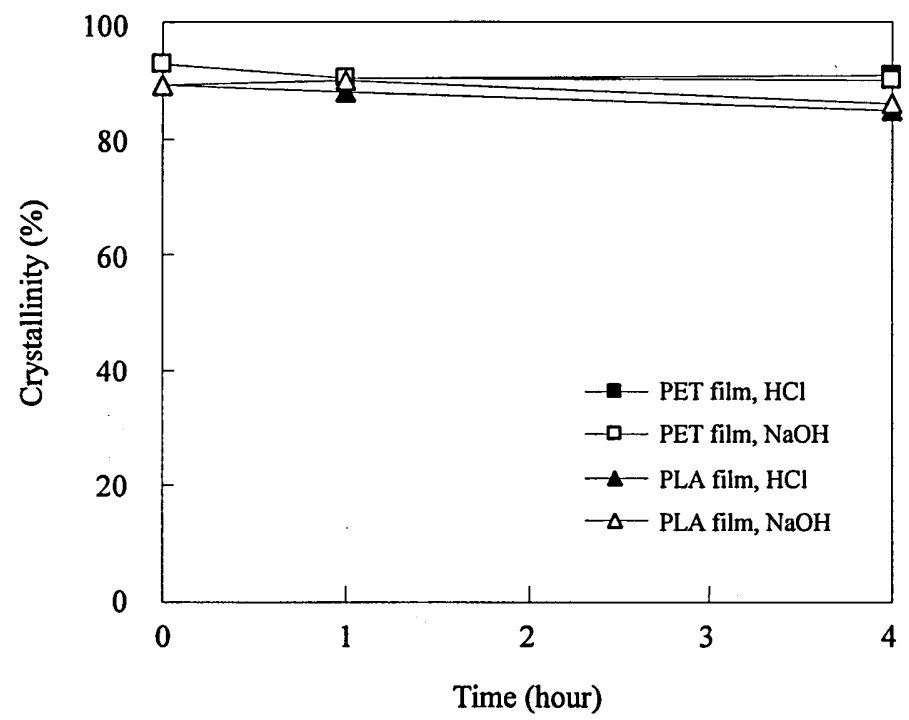

Fig. 4. Changes in the crystallinity of PLA and PET films by chemical treatments with $1 \mathrm{M} \mathrm{HCl}$ or with $1 \mathrm{M} \mathrm{NaOH}$ at $20^{\circ} \mathrm{C}$.

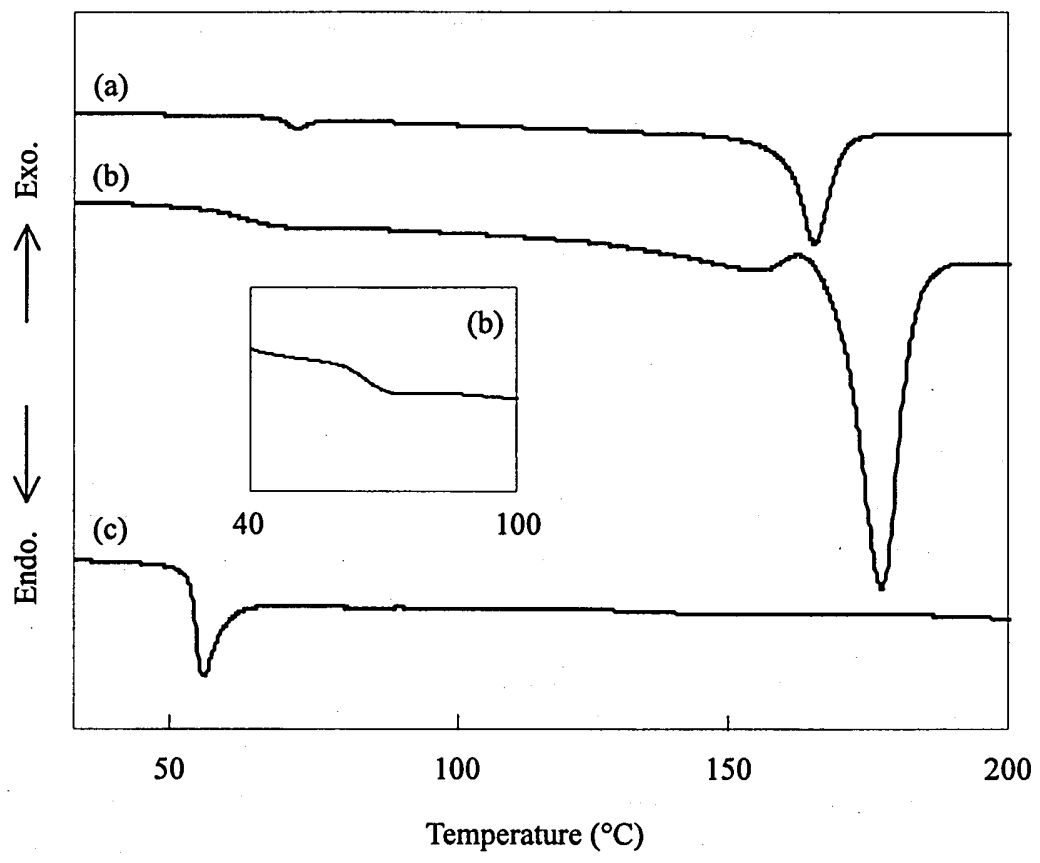

Fig. 5. DSC profiles of PLA film (a), PLLA (b) and PDLLA (c). 
perature increased over the PLLA Tg. The PDLLA was quite rapidly finished to melt over the $\mathrm{Tg} 55^{\circ} \mathrm{C}$ because of having no rubber-like property; and then the self-assembling aggregation occurred, resulting in a remarkable reduction of specific surface area and thus of chemical degradability as shown in Fig. 2.

Figure 6 shows the NIR-FT Raman spectra of PLA film (a), PLLA (b) and PDLLA (c).

Table 2. Melting point and glass transition point (Tg) of PLA film, PLLA and PDLLA.

\begin{tabular}{lcc}
\hline Sample & Melting point $\left({ }^{\circ} \mathrm{C}\right)$ & $\mathrm{Tg}\left({ }^{\circ} \mathrm{C}\right)$ \\
\hline PLA film & 165.6 & 70.0 \\
PLLA & 176.9 & 66.1 \\
PDLLA & - & 55.0 \\
\hline
\end{tabular}

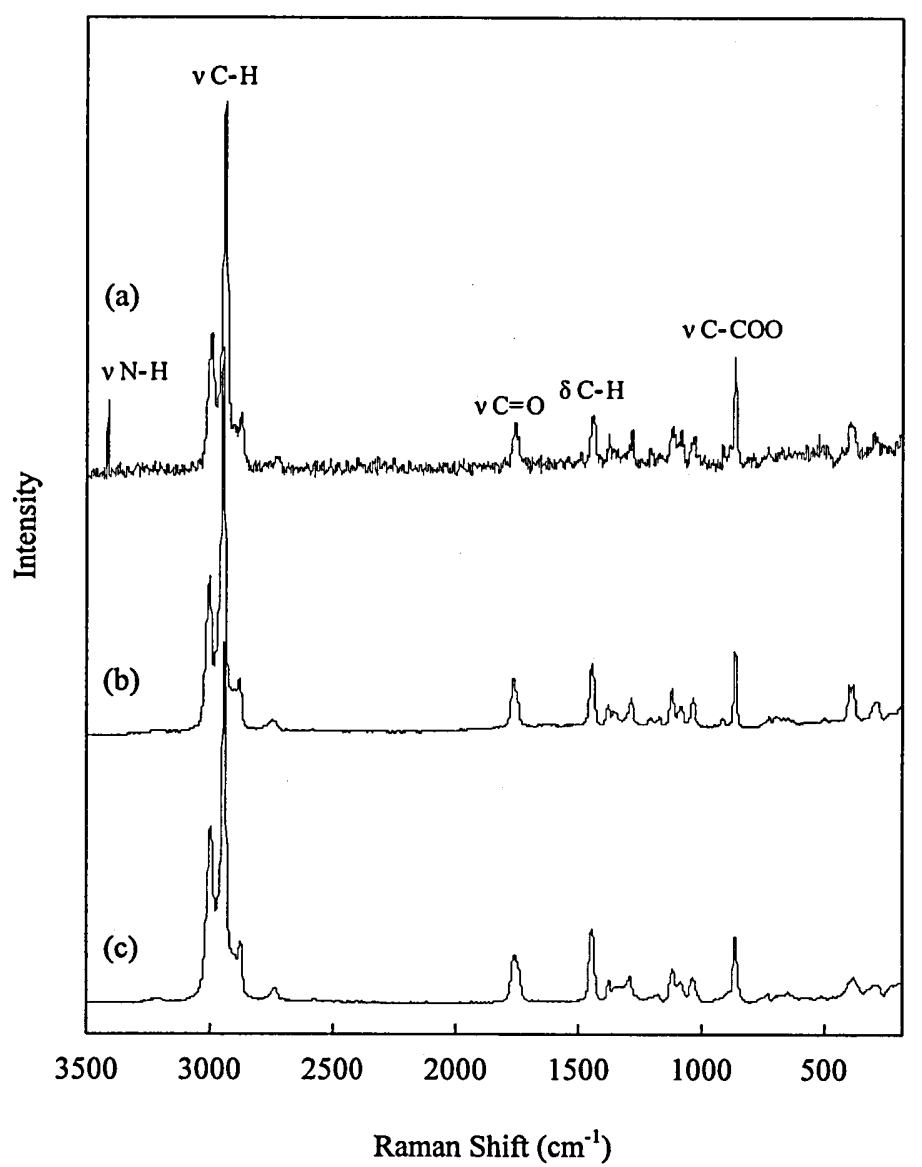

Fig. 6. Raman spectra of PLA film (a), PLLA (b) and PDLLA (c). 
In the PLA film, characteristic Raman shift was observed at $3420 \mathrm{~cm}^{-1}$ in correspondence to $\mathrm{N}-\mathrm{H}$ stretching. The $\mathrm{N}$-containing components are not derived from the PLA, and unknown components must exist in the commercial PLA products, somewhat contribut-

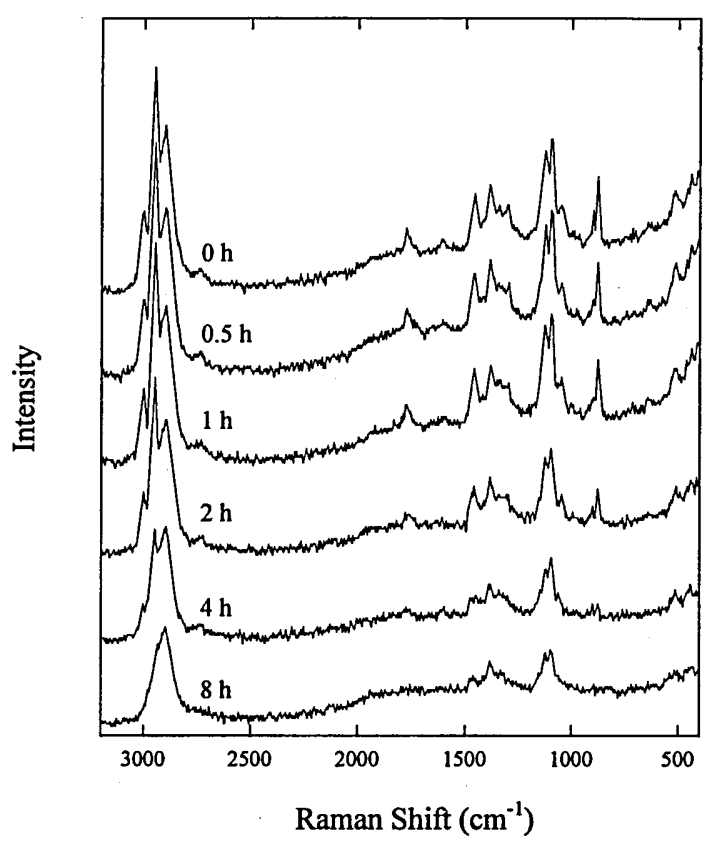

Fig. 7. Changes in the Raman shifts of PLA-laminated paperboard by chemical treatment with $1 \mathrm{M} \mathrm{NaOH}$ at $20^{\circ} \mathrm{C}$.

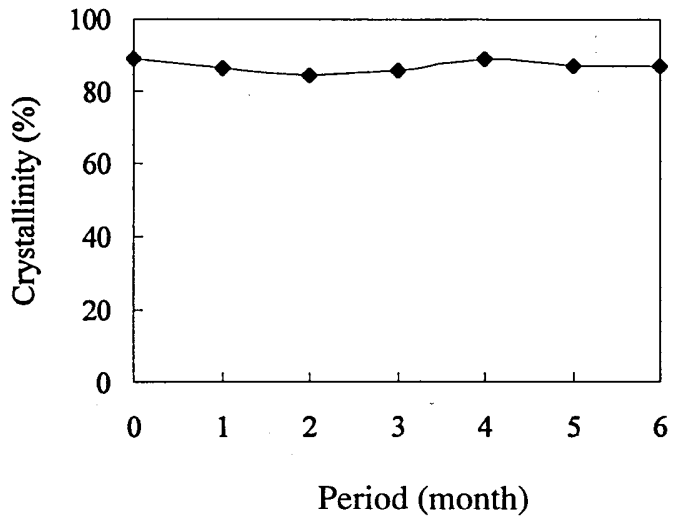

Fig. 8. Changes in the crystallinity of PLA film by in-soil burial test. 
ing to the physical properties. Figure 7 illustrates the changes in the Raman shifts of PLA-laminated paperboards treated with $1 \mathrm{M} \mathrm{NaOH}$. Only PLA-related peaks clearly decreased with time, although the paper-related peaks slightly became weaker and

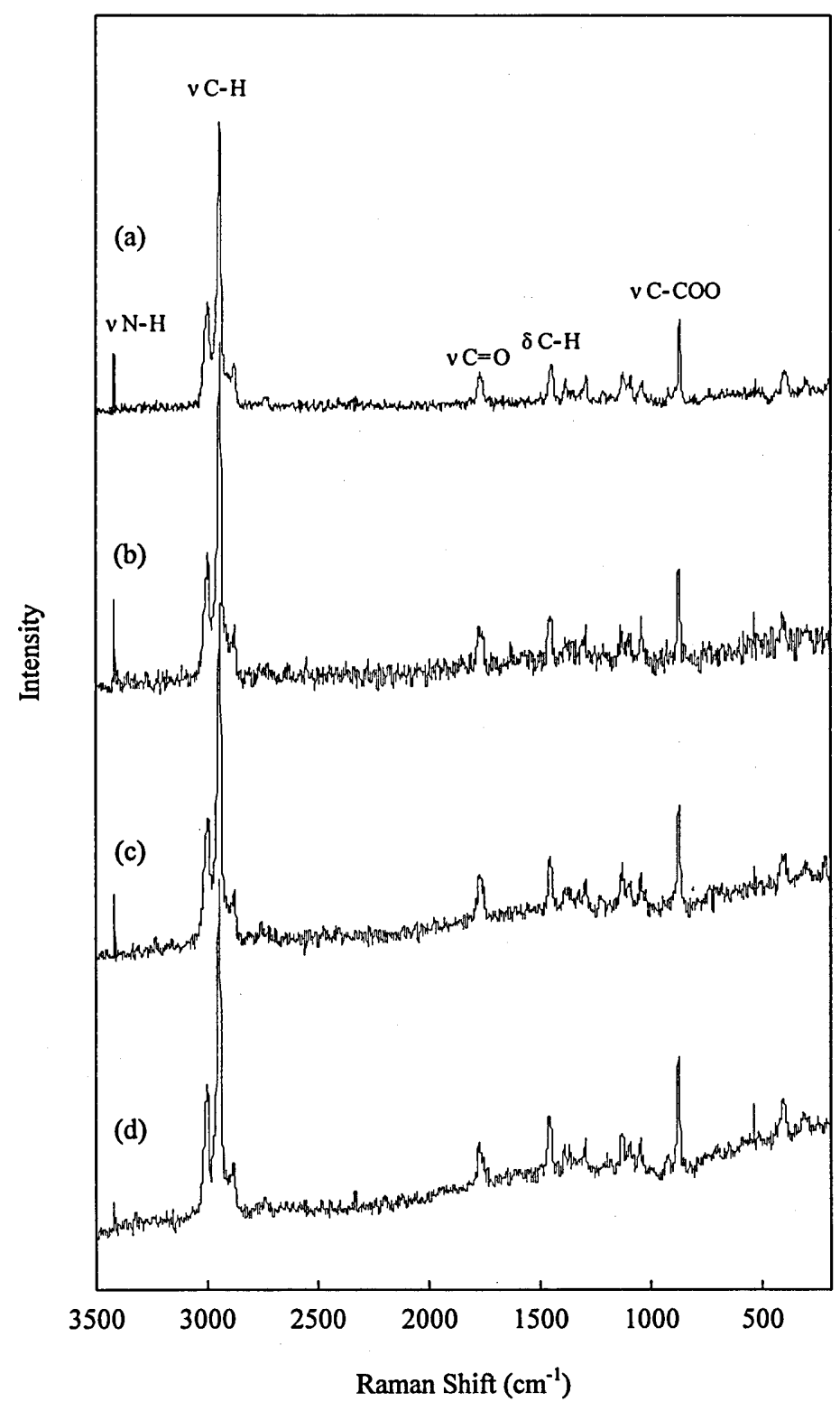

Fig. 9. Changes in the Raman shifts of PLA film by in-soil burial test for 0 month (a), 1 month (b), 3 months (c) and 6 months (d). 
broader even after the 8-hour treatment. Raman intensity reflects the sample crystallinity to some extent; however, the PLA crystallinity was almost constant as shown in Fig. 4; and thus the reduction in the Raman intensity must be induced by the sample loss as shown in Fig. 1. The PLA products demonstrated a high resistance to acid hydrolysis and at room temperature alkaline-resistive properties were also indicated in the PLA components with relatively high crystallinity; however, the quick decomposition by a dilute alkaline was observed in amorphous PDLLA and in all PLAs over their Tg.

\section{Biological degradation of PLA products}

Figure 8 shows the changes in the PLA crystallinity during in-soil burial periods of $0-6$ months. On the biological degradation, the PLA film remained almost unchanged even after buried in soil for six months, supporting the results from external observation reported in our previous study (Kanie et al., 2002). At the burial test, quantitative gravimetric analysis was difficult because the reproducibility becomes a serious problem. Weaker Raman band for N-H stretching in the in-soil-treated PLA film was observed as the burial period went longer in Figure 9, however significant difference in the PLA-related portion was not confirmed. Thermodynamic properties were also less variable (data not shown). These analytical results suggested that the commercial PLA products were slightly degraded in soil, and their performance for biodegradability was overestimated. Biodegradation mechanisms of polyester plastics such as PLA have been accounted for by non-enzymatic hydrolysis and sequential biotic metabolism (Tsuji et al., 2001). However, natural circumstances, water and soil systems, are in general maintained at the acidic-to-neutral conditions; and the results obtained in this study revealed that the PLA products show an extremely high resistance to acid hydrolysis in any case. Hence, the initial non-enzymatic hydrolysis may not occur in natural environments. On the other hand, the paper substrate in paperboards laminated with PLA film was immediately decomposed in soil possibly by in-situ microorganisms, as reported (Kanie et al., 2002). Most commercial paper products are made in alkaline papermaking systems, and thus the paper waste possibly can show some alkalinity. Therefore, the material design for combining a high degradable paper with a low degradable PLA is a promising concept for manufacturing high performance composites with biodegradability.

\section{REFERENCES}

Amass, W., A. Amass and B. Tighe 1998 A review of biodegradable polymers. Polymer International, 47: 89-144

Anderson, J. M. and M. S. Shive 1997 Biodegradation and biocompatibility of PLA and PLGA microspheres. Adv. Drug Deliv. Reviews, 28: 5-24

Ikada, Y. and H. Tsuji 2000 Biodegradable polyesters for medical and ecological applications. Macromol. Rapid Commun., 21: 117-132

Jacobsen, S., P. H. Degee, H. G. Fritz, P. H. Dubois and R. Jerome 1999 Polylactide (PLA) - A new way of production. Polym. Eng. Sci., 39: 1311-1319

Kanie, O., H. Ishikawa, S. Ohta, T. Kitaoka and H. Tanaka 2002 Study on characteristics of paper laminated with biodegradable plastics: 1. Burial test in soil. J. Fac. Agr., Kyushu Univ., 47: 89-96

Mohanty, A. K., M. Misra and G. Hinrichsen 2000 Biofibers, biodegradable polymers and biocomposites: An overview. Macromol. Mat. Eng., 276: 1-24

Nolasco-Hipolito, C., V. H. Thang, G. Kobayashi, K. Sonomoto and A. Ishizaki 2001 Lactic acid recovery from model solutions and fermentation broth by electrodialysis. J. Fac. Agr. Kyushu Univ., 45: 
$531-540$

Tsuji, H. and H. Muramatsu 2001 Blends of aliphatic polyesters: V Non-enzymatic and enzymatic hydrolysis of blends from hydrophobic poly (L-lactide) and hydrophilic poly (vinyl alcohol). Polym. Degradation Stability, 71: 403-413 